\title{
Numerical simulation of gas-solid flow in ducts by CFD techniques
}

\author{
R. K. Decker ${ }^{1}$, D. Noriler ${ }^{2}$, H. F. Meier ${ }^{2}$ \& M. Mori ${ }^{1}$ \\ ${ }^{1}$ Chemical Process Department, State University of Campinas, Brazil \\ ${ }^{2}$ Chemical Engineering Department, Regional University of Blumenau, \\ Brazil
}

\begin{abstract}
Numerical models are nowadays used on a large scale for the simulation of two-phase flow processes in the chemical industry, due mainly to their low implementation cost and important results. However, to find the best numerical models in such processes, validation with experimental data is required. In this sense, the main objective of this work is to apply a CFD model under Eulerian-Eulerian framework for the gas-particle flow, with the capability to predict the fluid dynamics of the two-phase flows in vertical and horizontal ducts separated by $90^{\circ}$ elbows. A three-dimensional and transient model has been applied for predictions of volume fractions, pressure, velocities and turbulence properties fields. For the momentum transfer between phases a drag model based on the application of "Churchill" asymptotes techniques was used to obtain a continuous function for all flow regimes. Furthermore, the wall effects over the particulate flow have been investigated. The mathematical model was applied in CFD commercial codes for numerical studies and compared with experimental data obtained by the research group at Lehigh University. The model is solved using the finite-volume method with variables located in a generalized co-ordinate system. The main results present the volume fraction and velocities profiles as a function of the time and position. In addition, the mean velocity and particle concentration of the radial profiles were compared with experimental data in different axial positions of the vertical duct. The results showed a good agreement for the mean particle velocity with the increment of the axial position.
\end{abstract} Keywords: CFD, gas-particle flow, ducts, elbows, numerical simulation. 


\section{Introduction}

In the chemical industry several processes occur in the presence of particulate flows, such as the up flow of catalytic particles in riser reactors in the petroleum industry and particle conveying systems found in the cement industry. From one first point of view the particulate flow in ducts seems to be not so difficult to study in comparison with other geometries where the particulate flow also exists. However, the flow phenomena existent in such flows is not simple. There are a lot of variables that may change the characteristics of the gas-solid flow in ducts, such as particle diameter distribution, particle-wall, particle-particle and particlegas interactions, operational conditions, geometry design and so on.

In order to analyze such variables, several research groups are dedicating efforts to obtaining experimental data for the gas-particle flow in different geometries and operational conditions. Tsuji and Morikawa [9] and Tsuji et al. [10] for instance developed a complete analysis of the gas-particle flow in the developed flow region of horizontal and vertical ducts by means of Laser Doppler Velocimeter (LDV). Some years later the research group at Lehigh University (Yilmaz and Levy [12]; Akilli et al [1]; Bilirgen and Levy [2]) analyzed the gas-particle flow by means of a fiber optic probe in the presence of different geometrical configurations and devices. The studied geometry was constituted of a vertical duct connected to the first by a $90^{\circ}$ elbow and a second horizontal duct connected with the vertical one with another $90^{\circ}$ elbow.

In order to understand the particle rope formation, mixture and dispersion phenomena in both sections, the authors evaluated devices for rope dispersion at the beginning of the vertical section just after the horizontal-to-vertical elbow and analyzed the parameters of the geometry and the flow operational conditions as well. As a chronological sequence of works showing the behavior of the twophase flow in ducts after the analysis of the developed and developing regions in horizontal and vertical ducts, as previously reported, Yang and Kuan [11] investigated the behavior of dilute turbulent particle flows inside a curved $90^{\circ}$ bend using a 2D Laser Doppler Anemometry (LDA). As a result the authors observed the rope formation phenomena inside the bend.

Even so, experimental measurements can bring information about the gasparticle conveying as previously described, although simulations of the twophase flow system are also nowadays required. Basically, two phenomenological approaches are employed in the representation of the two-phase flows: the Eulerian-Lagragian (E-L) and the Eulerian-Eulerian (E-E) models. Several numerical studies showing the two-phase flow behavior in ducts were developed in the literature using the E-L approach, $[1,2,5,6,12]$, and the E-E approach $[4,7]$. It is known that the E-L approach requires a great amount of tracking particles to describe efficiently the two-phase flow in ducts, which increases the computational time. Furthermore, the particle-particle and particle-wall interactions are very sensitive to the attributed restitution coefficient, which makes its application difficult for others flow and geometrical conditions. On the other hand, the E-E approach can be applied in a basic methodology by the adoption of an inviscid model, which does not have viscosity stress for the solid 
characterization. Furthermore, in such a model the solid agglomeration behave as a hypothetic fluid and interact with the gas phase by the drag force model (Decker [4]).

In this sense, the intention of this study is to compare the drag force model proposed by Coelho and Massarani [3] based on the application of "Churchill" asymptotes techniques with the model developed by Shiller and Neuman [8], as well as to compare the inviscid model proposed in this study with the model based on the kinetic theory of granular flow (KTGF) for the two-phase flow in a vertical section of the test facility proposed by Yilmaz and Levy [12]. For a better understanding of the flow phenomena, particle velocity and concentration maps are also presented for the measuring sections.

\section{Mathematical modeling}

The mathematical model applied in this work is based on two-fluid, threedimensional and transient flow approach in Eulerian-Eulerian framework. The main assumptions of the model are:

- Phases interpenetrating;

- Hypothetical fluid;

- $\quad$ The viscous stress and pressure of the particle phase is negligible;

- Particles are considered to be uniform spheres of same mean diameter;

- The momentum transfers is due only the drag force;

- The flow is isothermal.

\subsection{Conservation equations}

The equations of mass conservation for gas and solid phases are expressed by the eqn. (1) and eqn. (2), as follows:

$$
\begin{aligned}
& \frac{\partial}{\partial t}\left(f_{g} \rho_{g}\right)+\nabla .\left(f_{g} \rho_{g} \mathbf{v}_{g}\right)=0, \\
& \frac{\partial}{\partial t}\left(f_{s} \rho_{s}\right)+\nabla .\left(f_{s} \rho_{s} \mathbf{v}_{s}\right)=0 .
\end{aligned}
$$

Whereas the momentum equations for the gas and solid phases are expressed by eqn (3) and eqn (4), as follows

$$
\begin{gathered}
\frac{\partial}{\partial \mathrm{t}}\left(\mathrm{f}_{\mathrm{g}} \rho_{\mathrm{g}} \mathbf{v}_{\mathrm{g}}\right)+\nabla \cdot\left(\mathrm{f}_{\mathrm{g}} \rho_{\mathrm{g}} \mathbf{v}_{\mathrm{g}} \mathbf{v}_{\mathrm{g}}\right)=-\mathrm{f}_{\mathrm{g}} \nabla \cdot\left(\mathbf{T}_{\mathrm{g}}^{\mathrm{ef}}\right)+\mathrm{f}_{\mathrm{g}} \rho_{\mathrm{g}} \mathbf{g}-\nabla \mathrm{p}+\mathbf{F}_{\text {res }}, \\
\frac{\partial}{\partial \mathrm{t}}\left(\mathrm{f}_{\mathrm{s}} \rho_{\mathrm{s}} \mathbf{v}_{\mathrm{s}}\right)+\nabla \cdot\left(\mathrm{f}_{\mathrm{s}} \rho_{\mathrm{s}} \mathbf{v}_{\mathrm{s}} \mathbf{v}_{\mathrm{s}}\right)=\mathrm{f}_{\mathrm{s}} \rho_{\mathrm{s}} \mathbf{g}-\mathbf{F}_{\text {res }} .
\end{gathered}
$$

\subsection{Constitutive equations}

The effective tensor on the gas phase $\left(\mathbf{T}_{\mathrm{g}}^{\mathrm{ef}}\right)$ establishes a similar relation to the model for a general newtonian fluid, where the stress is directly proportional to the deformation rate $\left(\mathbf{T}_{\mathrm{g}}^{\mathrm{ef}}=-2 \mu^{\mathrm{ef}} \mathbf{D}_{\mathrm{g}}\right)$ and is giving by the expression: 


$$
\mathbf{T}_{\mathrm{g}}^{\mathrm{ef}}=-\mu^{\mathrm{ef}}\left[\nabla \mathbf{v}_{\mathrm{g}}+\left(\nabla \mathbf{v}_{\mathrm{g}}\right)^{\mathrm{T}}\right],
$$

where

$$
\mu^{\text {ef }}=\mu_{\mathrm{g}}+\mu^{(\mathrm{t})} \text {. }
$$

In eqn (6) the turbulent viscosity, $\mu^{(t)}$ is obtained from an isotropic turbulence model known as standard k- $\varepsilon$ model:

$$
\mu^{(\mathrm{t})}=\mathrm{C}_{\mu} \rho_{\mathrm{g}} \frac{\mathrm{k}_{\mathrm{g}}^{2}}{\varepsilon_{\mathrm{g}}} .
$$

There are two additional transport equations, one for the turbulent kinetic energy $(\mathrm{k})$ and another for the rate of dissipation of turbulent kinetic energy $(\varepsilon)$ :

$$
\begin{gathered}
\frac{\partial}{\partial t}\left(\mathrm{f}_{\mathrm{g}} \rho_{\mathrm{g}} \mathrm{k}_{\mathrm{g}}\right)+\nabla \cdot\left(\mathrm{f}_{\mathrm{g}} \rho_{\mathrm{g}} \mathbf{v}_{\mathrm{g}} \mathrm{k}_{\mathrm{g}}\right)=+\mathrm{f}_{\mathrm{g}} \nabla \cdot\left(\frac{\mu^{\mathrm{ef}}}{\sigma^{\mathrm{k}}} \nabla \mathrm{k}_{\mathrm{g}}\right)+\mathrm{f}_{\mathrm{g}}\left(\mathrm{G}_{\mathrm{g}}-\rho_{\mathrm{g}} \varepsilon_{\mathrm{g}}\right), \\
\frac{\partial}{\partial}\left(\mathrm{f}_{\mathrm{g}} \rho_{\mathrm{g}} \varepsilon_{\mathrm{g}}\right)+\nabla \cdot\left(\mathrm{f}_{\mathrm{g}} \rho_{\mathrm{g}} \mathbf{v}_{\mathrm{g}} \varepsilon_{\mathrm{g}}\right)=\mathrm{f}_{\mathrm{g}} \nabla \cdot\left(\frac{\mu^{\mathrm{ef}}}{\sigma^{\varepsilon}} \nabla \varepsilon_{\mathrm{g}}\right)++\mathrm{f}_{\mathrm{g}}\left(\mathrm{C}_{\mathrm{g}} \mathrm{G}_{\mathrm{g}}-\mathrm{C}_{2} \rho_{\mathrm{g}} \varepsilon_{\mathrm{g}}\right) \frac{\varepsilon_{\mathrm{g}}}{\mathrm{k}_{\mathrm{g}}} .
\end{gathered}
$$

The turbulent kinetic energy generation $\left(\mathrm{G}_{\mathrm{g}}\right)$ for the gas phase is obtained by the tensorial product, which is denominated as double dot product, between the Reynolds tensor $\left(\mathbf{T}_{\mathrm{g}}^{(\mathrm{t})}\right)$ and the velocity gradient for the gas phase $\left(\nabla \mathbf{v}_{\mathrm{g}}\right)$, as follows:

$$
\mathrm{G}_{\mathrm{g}}=-\mathbf{T}_{\mathrm{g}}^{(\mathrm{t})}: \nabla \mathbf{v}_{\mathrm{g}} \cdot
$$

The resistive force between the phases $\left(\mathbf{F}_{\text {res }}\right)$ is modeled by the equation:

$$
\mathbf{F}_{\text {res }}=\beta_{\mathrm{g}, \mathrm{s}}\left(\mathbf{v}_{\mathrm{g}}-\mathbf{v}_{\mathrm{s}}\right) \text {. }
$$

The interface coefficient $\beta_{\mathrm{g}, \mathrm{s}}$ can be predicted by dilute flow $\left(\mathrm{f}_{\mathrm{g}}>0,8\right)$, as:

$$
\beta_{\mathrm{g}, \mathrm{s}}=\frac{3}{4} \mathrm{C}_{\mathrm{D}} \frac{\mathrm{f}_{\mathrm{s}} \rho_{\mathrm{g}}\left|\mathbf{v}_{\mathrm{g}}-\mathbf{v}_{\mathrm{s}}\right|}{\mathrm{d}_{\mathrm{p}}} .
$$

\subsubsection{Two correlations for the drag coefficient}

2.2.1.1 Coelho and Massarani correlation The drag coefficient (Cd) prediction is made for the studied flows by means of a Coelho and Massarani [3] correlation, valid for all Reynolds number range avoiding possible discontinuities provoked by the flow change, typical of a standard discontinue model where its adopted for each Reynolds number range. The correlation is:

$$
\mathrm{Cd}=\left[\left(\frac{24}{\mathrm{~K}_{1} \mathrm{Re}_{\mathrm{p}}}\right)^{0.85}+\mathrm{K}_{2}^{0.85}\right]^{1.18},
$$

with $\mathrm{K}_{1}=0.843 . \log _{10}\left(\frac{\phi_{\mathrm{p}}}{0.065}\right)$ and $\mathrm{K}_{2}=5.31-4.88 \phi_{\mathrm{p}}$.

The particle Reynolds number $\left(\operatorname{Re}_{\mathrm{p}}\right)$ is:

$$
\operatorname{Re}_{\mathrm{p}}=\frac{\rho_{\mathrm{g}}\left|\mathbf{v}_{\mathrm{g}}-\mathbf{v}_{\mathrm{s}}\right| \mathrm{d}_{\mathrm{p}}}{\mu_{\mathrm{g}}} .
$$


2.2.1.2 Shiller and Nauman correlation Three regimes are considered:

- Stokes Regime:

$$
\mathrm{Cd}=24 / \mathrm{Re}_{\mathrm{p}} \quad \text { for } \quad 0<\mathrm{Re}_{\mathrm{p}} \leq 200 .
$$

- Viscous Regime:

$$
\mathrm{Cd}=\frac{24}{\operatorname{Re}_{\mathrm{p}}}\left[1+0.15 \mathrm{Re}_{\mathrm{p}}^{0.687}\right] \text { for } \quad 200<\operatorname{Re}_{\mathrm{p}} \leq 2500 .
$$

- Inertial Regime:

$$
\mathrm{Cd}=0.44 \text { for } 2500<\mathrm{Re}_{\mathrm{p}} .
$$

\subsubsection{Kinetic theory of granular material model}

With the aim to verify the inviscid approach, simulations applied the kinetic theory to predict the stress in the solid phase. So, the solid stress $\boldsymbol{\Gamma}_{\mathrm{s}}$ can be written as follow:

$$
\mathbf{T}_{s}=-p_{s} \delta+\left(\lambda_{s}-\frac{2}{3} \mu_{s}\right) \nabla \cdot \mathbf{v}_{s}+-\mu\left[\nabla \mathbf{v}_{s}+\left(\nabla \mathbf{v}_{s}\right)^{T}\right] .
$$

The solid pressure, ps, and the bulk, $\lambda_{\mathrm{s}}$, and shear, $\mu_{\mathrm{s}}$, viscosities are given in terms of granular temperature, $\Theta_{\mathrm{s}}$, the radial distribution function, $\mathrm{g}_{0}$, the coefficient restitution, e, and the particle diameter, i.e.,

$$
\begin{gathered}
p_{s}=\rho_{s} f_{s} \Theta_{s}\left(1+2(1+e) g_{0} f_{s}\right), \\
\lambda_{s}=\frac{4}{3} f_{s} \rho_{s} d_{p} g_{0}(1+e)\left(\frac{\Theta_{s}}{\pi}\right)^{0.5}, \\
\mu_{s}=\frac{10 \sqrt{\pi} \rho_{s} d_{p} \Theta^{0.5}}{96(1+e) g_{0} f_{s}}\left(1+\frac{4}{5}(1+e) g_{0} f_{s}\right)^{2}+\frac{4}{5} f_{s} \rho_{s} d_{p} g_{0}(1+e)\left(\frac{\Theta_{s}}{\pi}\right)^{0.5} .
\end{gathered}
$$

The radial distribution function is given by:

$$
g_{0}=0.6\left(1-\left(\frac{f_{s}}{f_{s, \max }}\right)^{1 / 3}\right)^{-1} .
$$

and the granular temperature is obtained from an equation:

$$
\Theta_{s}=\left(-p_{s} \delta+\sigma_{s}\right) \cdot \nabla \mathbf{v}_{s} .
$$

Where the dissipation of fluctuation energy takes the form:

$$
\mathcal{\Theta}_{s}=3\left(1-e^{2}\right) g_{0} f_{s}^{2} \rho_{s} \Theta_{s}\left(\frac{4}{d_{p}}\left(\frac{\Theta_{s}}{\pi}\right)^{0.5}-\nabla \cdot \mathbf{v}_{s}\right) .
$$

\subsection{Boundary conditions}

The boundary conditions for physical frontiers of the gas-solid flow in ducts are as follows. 


\subsubsection{Inlet}

It is adopted a uniform and constant gas-solid flow with an initial velocity for both phase $\left(\mathrm{U}_{0}=29 \mathrm{~m} / \mathrm{s}\right)$. All other flow properties are considered uniform.

\subsubsection{Outlet}

Constant pressure with continuity conditions considered for all flow properties.

\subsubsection{Wall}

It is considered null derivates for volumetric fractions (impermeable frontiers), and wall logarithm function for the turbulent properties. The wall condition for the gas velocity for all numerical studies was considered to be no-slip and for the particle velocity, no-slip and slip, depending on the desired simulation condition.

\section{Numerical modeling}

The numerical simulations where conducted by a CFD commercial package, the CFX 4.4. The pressure-velocity coupling applied was SIMPLEC, and the interpolation scheme of first order was the UPWIND due to the strong convective component of the gas-solid transport. The algorithm was applied with the AMG and ICCG proceeding to solve the discrete algebraic equations. The convergence criteria for all studied cases was $1.10^{-4}$ for the Euclidian norm in the mass source. The relaxation factors were used only for the turbulent kinetic energy $(\mathrm{k})$ and for its dissipation rate $(\varepsilon)$ in the turbulence model with values equal to 0.7 to guarantee stability and convergence. The interactions were solved for a time step equal to $5.10^{-4}$ using one time typical implicit integration.

\section{Case study}

Fig. 1 presents the geometrical system proposed by Yilmaz and Levy [12] for the analysis of the gas-solid flow and details of the numerical grid used for the simulation process. The system is composed of three different duct sections, two horizontal and one vertical $\left(\mathrm{L}_{1}, \mathrm{H}\right.$ and $\left.\mathrm{L}_{2}\right)$, connected among them by $90^{\circ}$ elbows with bend ratio equal 1.5 . The mass load ratio $\mathrm{A} / \mathrm{F}=1$ was used for all numerical simulations. The physical and geometrical properties are showed in Table 1.

\section{Results}

For the analysis of the gas-solid flow in a vertical duct a sequence of studies was developed. The first study was the investigation of the drag force model

Table 1: $\quad$ Physical and geometrical properties.

\begin{tabular}{|c|c|c|c|c|}
\hline & $\rho_{\mathrm{g}}\left(\mathrm{K}_{\mathrm{g}} / \mathrm{m}^{3}\right)$ & 1.225 & $\phi_{\mathrm{p}}$ & 1.000 \\
\cline { 2 - 5 } Physical and & $\mu_{\mathrm{g}}(\mathrm{Kg} / \mathrm{m} . \mathrm{s})$ & $1.850 \mathrm{E}-05$ & $\mathrm{D}(\mathrm{m})$ & 0.154 \\
\cline { 2 - 5 } $\begin{array}{c}\text { Geometrical } \\
\text { Properties }\end{array}$ & $\rho_{\mathrm{s}}\left(\mathrm{K}_{\mathrm{g}} / \mathrm{m}^{3}\right)$ & 1680.000 & $\mathrm{~L}_{1}$ and $\mathrm{L}_{2}(\mathrm{~m})$ & 6.100 \\
\cline { 2 - 5 } & $\mathrm{d}_{\mathrm{p}}(\mathrm{m})$ & $75 \mathrm{E}-06$ & $\mathrm{H}(\mathrm{m})$ & 3.400 \\
\hline
\end{tabular}


proposed by Coelho and Massarani [3] in comparison with the default model implemented in the CFD software developed by Schiller and Neuman [8]. The criteria adopted to define each model are the comparison with the experimental data obtained by Yilmaz and Levy [12] as well as the convergence rate. The results presented in fig. 2 in terms of particle velocity shows that both models are equally far from the experimental data. However the Coelho and Massarani model showed much better convergence stability than the Shiller and Neuman model which hardly reduced the computational time for the mass flow balance convergence. Due to this criteria and not just the comparison with the experimental data the Coelho and Massarani model was chosen to be used in this study for other developments.
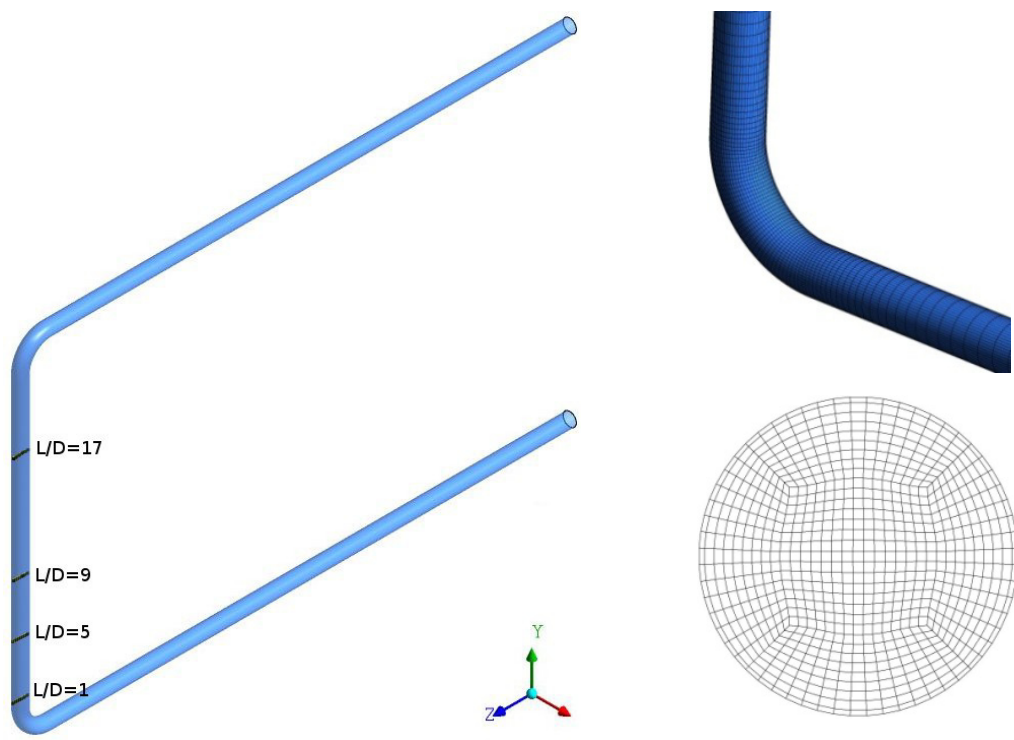

Figure 1: Details of geometry and numerical grid.

Once the drag model is defined the analysis of the inviscid model can be carried out and compared with a model based on the theory of granular materials (KTGF). For both developments the drag force model of Coelho and Massarani [3] has been applied. Fig. 3 shows for $\mathrm{L} / \mathrm{D}=17$ that the inviscid model seems to disperse the particulate phase in the transversal section of the duct much better than the KTGF model and more likely the experimental data of Yilmaz and Levy [12]. In this way, the inviscid model showed to be a relevant tool to be applied for the gas-solid flow modeling due to its simple characteristics when compared with E-L models and some others E-E models in the presence of several functions for the solid pressure and viscosity such as KTGF.

The results previously presented considered the no-slip condition at the wall for the particulate phase. However, owing the flow direction change promoted by the $90^{\circ}$ elbows an analysis of the wall treatment has been developed and 
presented in fig. 4. As result it is observed that the wall condition just interfere in the region near the wall. However when compared with the experimental data the slip condition showed to be apparently consistent near the wall. This comparison can just be done in the $\mathrm{x} / \mathrm{D}$ region near to zero due to the better experimental data acquisition at this region near the wall.

Considering that the slip condition at the wall showed a reasonable adjustment in these previous numerical experiments combined with the inviscid proposed model, and considering that the Coelho and Massarani model showed to be faster in the convergence of the mass balance between inlet and outlet, a complete analysis of the two-phase flow in a vertical section is developed. For this analysis snapshots of particle concentration, particle velocity and tangential vectors are showed for $\mathrm{L} / \mathrm{D}=1,5,9$ and 17 and presented in fig. 5. As can be seen in fig. $5 \mathrm{a}$ and fig. $5 \mathrm{~b}$ for $\mathrm{L} / \mathrm{D}=1$ the particle flow is concentrated in the outer wall of the duct $\left(\mathrm{x} / \mathrm{D}=0\right.$ and $\left.\mathrm{Cp}=2 \mathrm{Kg} / \mathrm{m}^{3}\right)$ due to the tangential forces acting in the particulate flow by the presence of a $90^{\circ}$ elbow.

At the same instant that the ropes are formed, secondary flows in the order of $5 \mathrm{~m} / \mathrm{s}$ start to act, as showed in fig. $5 \mathrm{c}$, redirecting and dispersing the ropes in direction to the opposite wall $(\mathrm{x} / \mathrm{D}=1)$ of the vertical section. Owing to the

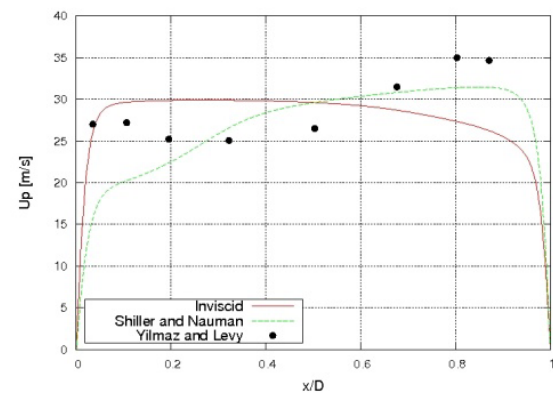

Figure 2: Drag force model analysis.

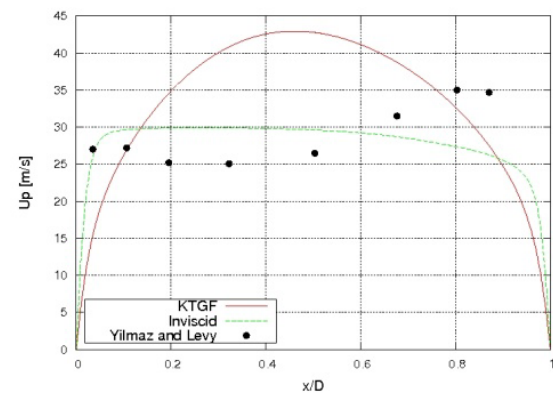

Figure 3: Inviscid model analysis.

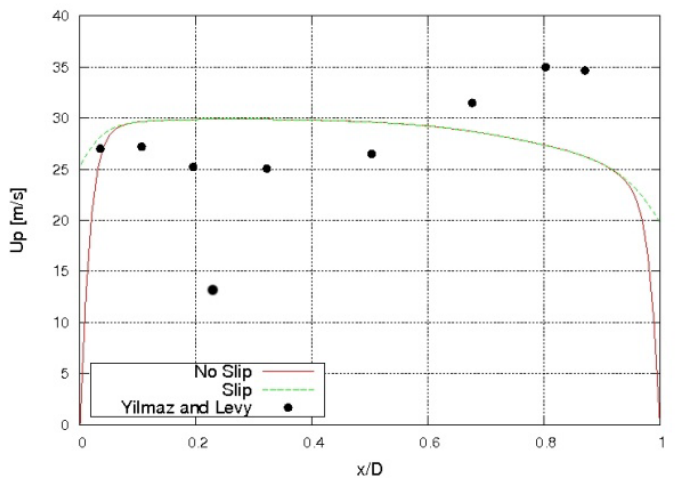

Figure 4: Wall treatment condition. 


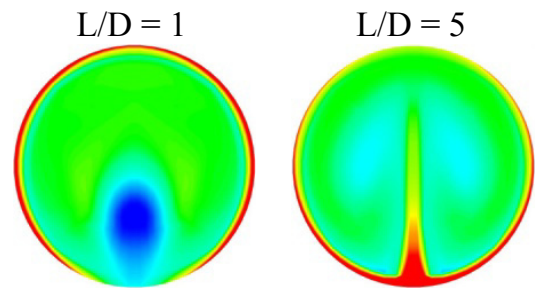

a) Particle Concentration
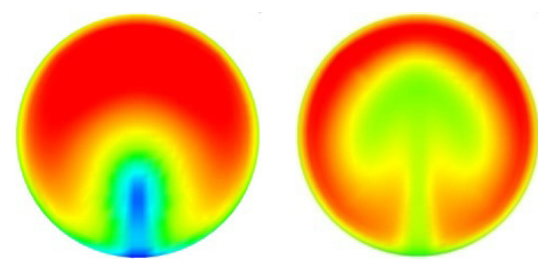

b) Particle Axial Velocity
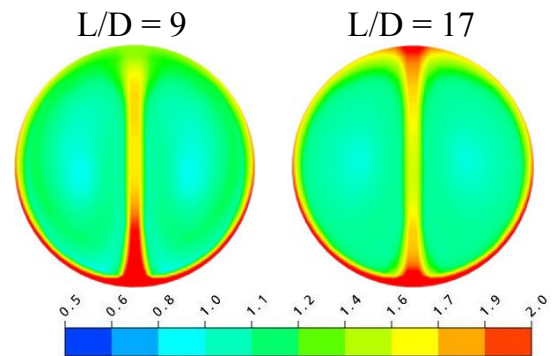

[ kg m-3 ]
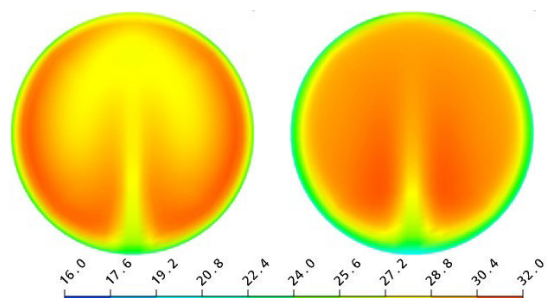

$\left[\mathrm{m} \mathrm{s}^{\wedge}-1\right]$

c) Tangencial Vector Plot

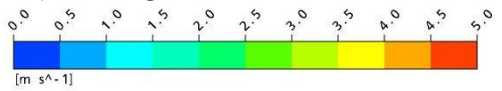

Figure 5: Snapshots in different positions (L/D = 1, 5, 9 and 17) for the vertical measuring section. a) Particle concentration ranging from $0,5 \mathrm{Kg} / \mathrm{m}^{3}$ to $2 \mathrm{Kg} / \mathrm{m}^{3}$; b) particle axial velocity ranging from 16 $\mathrm{m} / \mathrm{s}$ to $32 \mathrm{~m} / \mathrm{s}$; c) tangential vector plot for the particle phase ranging from 0 to $5 \mathrm{~m} / \mathrm{s}$.

presence of secondary flows the axial particle velocity is also redirect in direction to the inner wall $(\mathrm{x} / \mathrm{D}=1)$ with the increment of the $\mathrm{L} / \mathrm{D}$ region of the vertical section as seen for $\mathrm{L} / \mathrm{D}=5$ and herewith the particle concentration.

After its redirection the secondary flows becomes weak and particle axial velocity and concentration are dispersed along the transversal section with the increment of axial position. These observations are showed in fig. 5a and 5b for L/D regions equal to 9 and 17. Fig. 5c also shows that secondary flows also becomes weak and more homogeneous with the increment of axial position. These observations were also reported by Yilmaz and Levy [12] in their studies. 


\section{Conclusions}

The CFD tools presented and discussed in this work makes possible to know better the gas-solid flow conditions in a vertical duct and how the secondary flow interact with the axial flow dispersing ropes. It is possible to verify the rope formation in the outer wall formed just after the elbow due to the centrifugal forces and the dispersion toward with the increment of the axial position. Furthermore, the inviscid model showed to be a relevant tool to be applied for the two-phase flow modeling due to its simple characteristics when compared with E-L models and some others E-E models in the presence of several functions for the solid pressure and viscosity such as KTGF.

\section{References}

[1] Akilli, H., Levy, E. K. \& Sahin, B., Gas-solid behavior in a horizontal pipe after a $90^{\circ}$ vertical-to-horizontal elbow. Powder Technology, 116, pp. 4352, 2001.

[2] Bilirgen, H. \& Levy, E. K., Mixing and dispersion of particle ropes in lean phase pneumatic conveying. Powder Technology, 119, pp. 134-152, 2001.

[3] Coelho, R. M. L. \& Massarani, G. Fluidodinâmica de partículas: ainda sobre correlações em base aos dados experimentais de Pettyjohn e Christiansen. Relatório LSP/COPPE 1/96, 1996.

[4] Decker, R. K.; Modelagem e simulação tridimensional transiente do escoamento gás-sólido, Campinas: Faculdade de Engenharia Química da Unicamp, Tese, 2003.

[5] Huber, N. \& Sommerfeld, M., Modeling and numerical calculation of dilute-phase pneumatic conveying in pipe systems. Powder Technology, 99, pp. 90-101, 1998.

[6] Kuan, B., Yang, W. \& Schwarz, M. P., Dilute gas-solid two-phase flows in a curved $90^{\circ}$ duct bend: CFD simulation with experimental validation. Chemical Engineering Science, 62, pp. 2068-2088, 2007.

[7] Mohanarangam, K., Tian, Z. F. \& Tu, J. Y., Numerical simulation of turbulent gás-particle flow in a $90^{\circ}$ Bend: Eulerian-Eulerian approach. Computers \& Chemical Engineering, 32, pp. 561-571, 2008.

[8] Shiller, L. \& Neuman, A. Z., A drag coefficient correlation, Verein Deutschen Ingenieure Zeitung, 77, pp. 318-320, 1933.

[9] Tsuji, Y. \& Morikawa, Y., LDV measurements of an air-solid two-phase flow in a horizontal pipe. J. Fluid Mech., 120, pp. 385-409, 1982.

[10] Tsuji, Y., Morikawa, Y. \& Shiomi, H., LDV measurements of an air-solid two-phase flow in a vertical pipe. J. Fluid Mech., 139, pp. 417-434, 1984.

[11] Yang, W. \& Kuan, B., Experimental investigation of dilute turbulent particulate flow inside a curved $90^{\circ}$ bend. Chemical Engineering Science, 61, pp. 3593-3601, 2006.

[12] Yilmaz, A. \& Levy, E. K., Formation and dispersion of ropes in pneumatic conveying. Powder Technology, 114, pp. 168-185, 2001. 